\title{
Optimizing Surface Finish in WEDM Using the Taguchi Parameter Design Method
}

Vamsi Krishna Pasam

vamsikrishna16@gitam.edu

\section{Surendra Babu Battula}

\author{
Madar Valli P. \\ Swapna M. \\ GITAM University \\ Dept. of Industrial Production Eng \\ 530045 Visakhapatnam, India
}

Wire electrical discharge machining (WEDM) is extensively used in machining of materials when precision is of major factor. Selection of optimum machining parameter combinations for obtaining higher accuracy is a challenging task in WEDM due to the presence of a large number of process variables and complex stochastic process mechanisms. In the present work, WEDM of titanium alloy (Ti6Al4V) is experimentally studied. The behavior of eight control parameters such as Ignition pulse current (A), Short pulse duration $(B)$, Time between two pulses $(C)$, Servo speed $(D)$, Servo reference voltage $(E)$, Injection pressure $(F)$, Wire speed $(G)$ and Wire tension $(H)$ on surface finish was studied using Taguchi parameter design. A mathematical model is developed by means of linear regression analysis to establish relationship between control parameters and surface finish as process response. An attempt is made to optimize the surface roughness prediction model using Genetic Algorithm (GA). Optimum values of control parameters at level $A_{1}, B_{1}, C_{1}, D_{3}, E_{1}, F_{3}, G_{2}, H_{3}$ for the selected range and workpiece material are obtained.

Keywords: WEDM, titanium alloy, surface roughness, modeling, genetic algorithm

\section{Introduction}

In the present scenario, the technology of wire electrical discharge machining (WEDM) is improved significantly to satisfy the requirements in various manufacturing fields. WEDM has been found to be an extremely potential electro-thermal process in the field of conductive material machining. WEDM has many applications in aerospace, automotive and medical industries to produce complex and intricate shapes. The most important performance factors in study of WEDM are material removal rate (MRR), surface finish and cutting width (kerf). They depend on machining parameters such as discharge current, pulse duration, pulse frequency, wire speed, wire tension, type of die electric fluid and dielectric flow rate. Selection of optimum machining parameter combinations for obtaining higher accuracy is a challenging task in WEDM due to the presence of a large number of process variables and complicated stochastic process mechanisms.

Ti-Al based alloys are utilized for structural applications in the range of $400^{\circ} \mathrm{C}$ to $800^{\circ} \mathrm{C}$, because of their long time strength at temperatures above $650^{\circ} \mathrm{C}$ and resistance to hot corrosion and erosion. These alloys are of great interest in the aerospace and automotive industries because of their high strength to weight ratios (Bradley, 1988). Most of these components are performed well in laboratory tests as well as in the field of engine valves, turbine blades, airframes, seal supports and cases (Voice, 1999 and Guedes et al., 2002). But, similarly to other inter metallic compounds, these alloys are not ductile and have low fracture toughness at room temperature, which makes them difficult to fabricate (Pan et al., 2001). In addition, the susceptibility of titanium to workharden during machining impairs their machinability; hence they are referred to as difficult-to-machine materials (Ezugwu et al., 2005).

\section{Literature Review}

In the past, various methods were employed to quantify the impact of control parameters on part surface quality. According to Trezise (1982), the fundamental limitations on machining accuracy are dimensional consistency of the wire and positional accuracy of the work table in WEDM process. Most of the uncertainties arise

Paper accepted January, 2010. Technical Editor: Anselmo Eduardo Diniz due to unsupported section of the wire. Rajurkar and Wang (1993) analyzed the wire rupture phenomena with a thermal model and experimental investigation carried out to determine the variation of machining performance (material removal rate and surface finish) with machining parameters. The material removal rate increases initially with decrease of pulse interval time. However, at a very short interval time, the gap becomes unstable, which leads to a reduction in the material removal rate. They observed that the surface quality decreases as the material removal rate increases. Huang et al. (1999) observed experimentally the effect of machining parameters on gap width, surface roughness and depth of white layer on the machined surface. It is found that the pulse-on time and the distance between the wire periphery and the workpiece surface are two significant factors affecting the machining performance. Tosun and Cogun (2003) reported the effect of machining parameters on wire wear ratio (WWR) based on the weight loss of wire in WEDM. It is found experimentally that the increasing pulse duration and open circuit voltage increase the wire wear ratio whereas the increasing wire speed decreases it. An attempt has been made by Liao et al. (1997) to unveil the influence of pulse-on time, pulse-off time, table feed-rate, flushing pressure, distance between wire periphery and workpiece surface on the machining performance of WEDM in finish cutting operations. Qualitatively, the pulse-on time $\left(T_{\mathrm{on}}\right)$ and the distance between the wire periphery and the workpiece surface $\left(D_{\mathrm{ww}}\right)$ have been found to be significant factors on gap width, surface roughness, and finish-cutting area ratio. It has also been found that a medium $D_{w w}$ can achieve a better surface roughness; adjusting $T_{\text {on }}$ and $D_{\text {ww }}$ can control the finish cutting process.

Keith and Duowen (2007) studied optimum cutting parameters in WEDM based on workpiece surface temperature distribution. FEM model was developed to compute thickness of the temperature affected layers for different cutting parameters based on a critical temperature value. Through minimizing the thickness of the temperature affected layers and satisfying a certain cutting speed, a set of the cutting process parameters was determined for the workpiece manufacture. The analyzed results have a good agreement with testing results. In another study (Fuzhu et al. 2007), the influence of machining parameters on surface roughness was investigated experimentally in WEDM. It was found that surface roughness can be improved by decreasing both pulse duration and discharge current. When the pulse energy per discharge is constant, short pulses and long pulses will produce the same surface 
roughness but dissimilar surface morphology and different material removal rates. The removal rate under short pulse duration is much higher than that under long pulse duration. Moreover, short pulse duration with a high peak value can generate better surface roughness, which a long pulse cannot do. It was also found that reversed polarity machining with appropriate pulse energy can improve the machined surface roughness a little better compared with the normal polarity in finish machining, but some copper from the wire electrode is accreted on the machined surface.

Sarkar et al. (2006) carried out wire electrical discharge machining of $\gamma$ titanium aluminide alloy and an advanced optimization strategy was proposed to determine the optimal combination of control parameters. A feed-forward neural network of type 6-15-3 was used to construct the WEDM process model. For better dimensional control, the wire offset value along with surface finish and cutting speed was considered as measure of process performance. A program was developed that will enable one to select the optimum parametric combination that will result in maximum productivity (cutting speed) while maintaining the required surface finish within limits. Additionally, the program is also capable of optimizing the machining process (under multi constraint conditions) while maintaining the surface roughness as well as the internal corner radius within specified limits. Jin et al. (2008) discussed the development of reliable multi-objective optimization based on Gaussian Process Regression (GPR) to optimize the high-speed wire-cut electrical discharge machining (WEDM-HS) process, considering mean current, on-time and offtime as input features and material remove rate and surface roughness as output responses. WEDM-HS is optimized with the reliability maximum MRR and minimum surface roughness as objectives. The experimental results show that GPR models have the advantage over other regressive models in terms of model accuracy and feature scaling and probabilistic variance.

Study of WEDM process requires number of parameters and laborious experimental work which requires more time and resources. Hence, to reduce the cost and time required to analyze WEDM process, optimization of the control parameters is necessary. Literature includes design of experiments that allow a systematic approach to demonstrate the effects of control parameters with minimum number of experimental trials. Some experiments are full-factorial designs with a small number of factors, while others are fractional factorial designs meant to screen factors for impact. Scott et al. (1991) developed a factorial design model to measure the process performance as a function of different control setting. The process is further optimized by introducing the concept of a nondominated point. Researchers (Ramakrishnan and Karunamurthy, 2006) described the multi objective optimization of the WEDM process using parametric design of Taguchi methodology. The effect of various machining parameters such as pulse on time, wire tension, delay time, wire feed speed, and ignition current intensity has been studied in machining heat-treated tool steel. It was identified that the pulse on time and ignition current intensity have influenced more than the other parameters considered in this study. Material removal rate, surface roughness, and wire wear ratio were improved concurrently by multi objective optimization tool. In another work (Mahapatra S. S. and Amar Patnaik, 2007), an attempt was made to determine the important machining parameters for performance measures like MRR, surface finish and kerf in the WEDM process. Factors like discharge current, pulse duration, and dielectric flow rate and their interactions have been found to play a significant role in rough cutting operations for maximization of MRR, minimization of surface roughness and minimization of cutting width using Taguchi's experimental design method. In this study, the relationships between control factors and responses are established by means of nonlinear regression analysis and Genetic
Algorithm (GA) is employed to optimize the wire electrical discharge machining process with multiple objectives.

An attempt has been made by Shajan and Shunmugam (2004) to analyze the metallurgical changes on the surface of the workpiece material (Ti64) due to WEDM process. X-ray analyses show that a mixture of oxides is formed on the surface of Ti64 machined by WEDM depending on the machining conditions. The effect of wire material on the machined surface is also studied. The parameters such as time between two pulses, pulse duration, injection pressure, wire speed and wire tension are identified as important process parameters of WEDM process, from metallurgical point of view. In order to obtain uniform surface characteristics, the coated wires are preferred over the uncoated wires. Time between two pulses is the most sensitive parameter that influences the formation of layer consisting of mixture of oxides. With a lower value of time between two pulses, a considerable reduction in the formation of oxides can be obtained. Shajan and Shunmugam (2005) used a multiple regression model to represent relationship between input and output variables, and a multi-objective optimization method based on a Non-Dominated Sorting Genetic Algorithm (NSGA) to optimize. Titanium alloy as workpiece material, and zinc coated brass wire as electrode wire were chosen for experimental work. Input variables considered in this work are ignition pulse current, pulse-off time, pulse duration, servo-control reference mean voltage, servo-speed variation, wire speed, wire tension and injection pressure to study the output variables cutting speed and surface finish. By optimization with NSGA, cutting velocity is increased for the same surface finish.

Though number of researches presented the study of optimizing WEDM process, these studies limit to few number of parameters. In the present work, wire electrical discharge machining of titanium alloy (Ti6Al4V) is studied with eight control parameters. A mathematical model is developed to predict surface roughness with control parameters in WEDM process. Regression analysis is carried out using the experimental data and an attempt is made to optimize the surface roughness prediction model using GA.

\section{Experimental Procedure}

Experimental trials were carried out in a ROBOFIL 310 high precision 5 axes CNC WEDM. The experimental setup is as follows: Zinc coated brass wire of $0.25 \mathrm{~mm}$ diameter is employed as electrode, titanium based-alloy (Ti6Al4V, Composition: $\mathrm{C}=0$ $0.08 \%, \mathrm{Fe}=0-0.25 \%, \mathrm{Al}=5.5-6.76 \%, \mathrm{O}=0-0.2 \%, \mathrm{~N}=0-0.05 \%$, $\mathrm{V}=3.5-4.5 \%, \mathrm{H}=0-0.375 \%$, balance $\mathrm{Ti}$ ) with tensile strength of 900-1000 MPa and hardness of 320-330 HB was chosen as the workpiece material. Workpiece dimensions were kept as $850 \mathrm{~mm}$ x $500 \mathrm{~mm}$ x $400 \mathrm{~mm}$ for all the experiments. Experiments were conducted to determine the surface quality of the workpiece with variation in input parameters. Taguchi method was used to determine optimal machining parameters for minimization of surface roughness in WEDM.

In this work, the behavior of eight control factors such as Ignition pulse current, Short pulse duration, Time between two pulses, Servo speed, Servo reference voltage, Injection pressure, Wire speed and Wire tension were studied. Control factors used and their levels with symbols are depicted in Table 1. The process response surface roughness is measured with Talysurf 10 (stylus radius: $0.0025 \mathrm{~mm}$, cut off length: $0.08-2.5 \mathrm{~mm}$ ). The control factors are used to select the best conditions for stability in the design of manufacturing process, whereas the noise factors denote all factors that cause variation. The experimental observations are further converted into a signal-to-noise $(\mathrm{S} / \mathrm{N})$ ratio using Eq. (1). Lower surface roughness value represents better machining performance; hence "lower is better" is selected for obtaining optimum machining 
performance. The signal-to-noise $(\mathrm{S} / \mathrm{N})$ ratio for "lower is better" is calculated (Mahapatra and Amar Patnaik, 2007) as follows:

$$
\eta=-10 \log \left[1 / n\left(\sum y_{i}^{2}\right)\right]
$$

where $\eta$ is the $\mathrm{S} / \mathrm{N}$ ratio, $\mathrm{y}_{\mathrm{i}}$ are the individual surface roughness measurements and $\mathrm{n}$ is the number of noise factors; in this case, $\mathrm{n}=8$. The array chosen was $\mathrm{L}_{27}\left(3^{8}\right)$, which has 27 rows corresponding to the number of experiments with 8 columns at three levels, as shown in Table 1.

Table 1. Control factors with symbols and their levels.

\begin{tabular}{|l|c|c|c|c|}
\hline Control Factor & $\begin{array}{c}\text { Symbol } \\
\text { used }\end{array}$ & Level 1 & Level 2 & Level 3 \\
\hline Ignition pulse current $(\mathrm{Amp})$ & $\mathrm{A}$ & 8 & 12 & 16 \\
\hline Short pulse duration $(\mu \mathrm{s})$ & $\mathrm{B}$ & 0.6 & 0.9 & 1.2 \\
\hline Time between two pulses $(\mu \mathrm{s})$ & $\mathrm{C}$ & 4 & 6 & 8 \\
\hline Servo speed $(\mu \mathrm{m} / \mathrm{min})$ & $\mathrm{D}$ & 4 & 8 & 12 \\
\hline Servo reference voltage $(\mathrm{V})$ & $\mathrm{E}$ & 30 & 45 & 60 \\
\hline Injection pressure $($ bar) & $\mathrm{F}$ & 2 & 3 & 4 \\
\hline Wire speed $(\mathrm{m} / \mathrm{min})$ & $\mathrm{G}$ & 8 & 10 & 12 \\
\hline Wire tension $(\mathrm{dN})$ & $\mathrm{H}$ & 1 & 1.1 & 1.2 \\
\hline
\end{tabular}

\section{Results and Discussion}

Experimental results show the effect of the eight control factors on surface roughness. Mean value of three measurements is used as a response value for surface roughness and standard deviation is calculated for each trial (Table 2). The dispersion of the surface roughness is within the close range, which is understood from these standard deviation values. Maximum standard deviation observed is 0.223 considering all the cases. Experimental results reveal the level to be chosen for the ideal cutting parameters as well as the relative effect of each parameter on the $\mathrm{S} / \mathrm{N}$ ratio.

Figure 1 shows the $\mathrm{S} / \mathrm{N}$ ratio for surface roughness with ignition pulse current. The increase of ignition pulse current will increase discharge energy. This increases the depth and diameter of discharging crater, raising the MRR, but deteriorating the surface finish. Hence, lower ignition pulse current is preferable to get better surface finish. S/N ratio values of spark time are presented in Fig. 2. Increase in spark time means discharge will remain longer time, and leads to high cutting speed and high discharge energy. This improves the MRR and worsens the surface finish. Hence, small spark time gives better surface finish. Comparison of the results obtained in the present work with those reported in the literature is difficult, because different materials, WEDM machines of different manufacturers and different machining parameters have been used by others. However, same trend is observed by Rajurkar and Wang (1993), same range of values are obtained by Shajan and Shunmugam (2005) with the parameters ignition pulse current and spark time influence on surface roughness. The relationship between surface roughness and time between pulses can be explained with the help of Fig 3. Delay time influences the voltage applied between electrodes. Increase in delay time reduces number of discharges in a given period of time and leads to decrease of gap voltage. Hence, discharge current increases for same power input and discharge energy increases, leading to increase in surface roughness. To achieve better surface finish lower values of delay time should be selected.

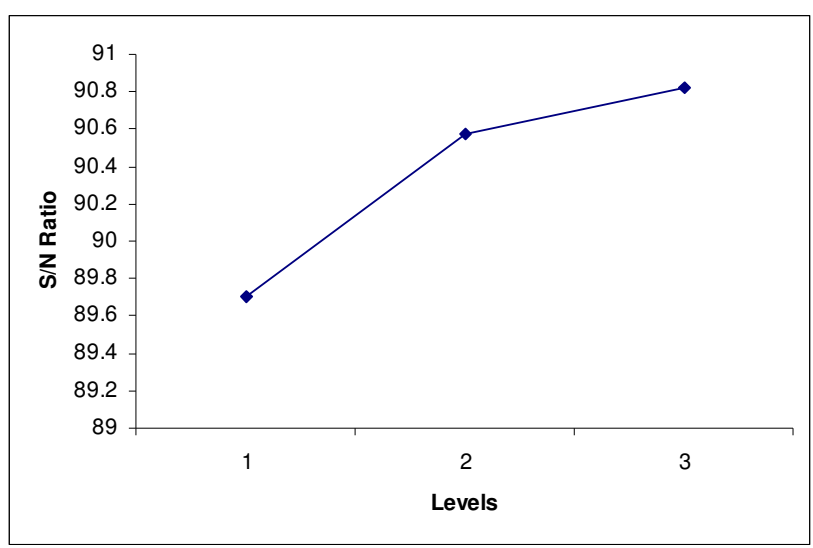

Figure 1. $\mathrm{S} / \mathrm{N}$ ratio for surface roughness with ignition pulse current.

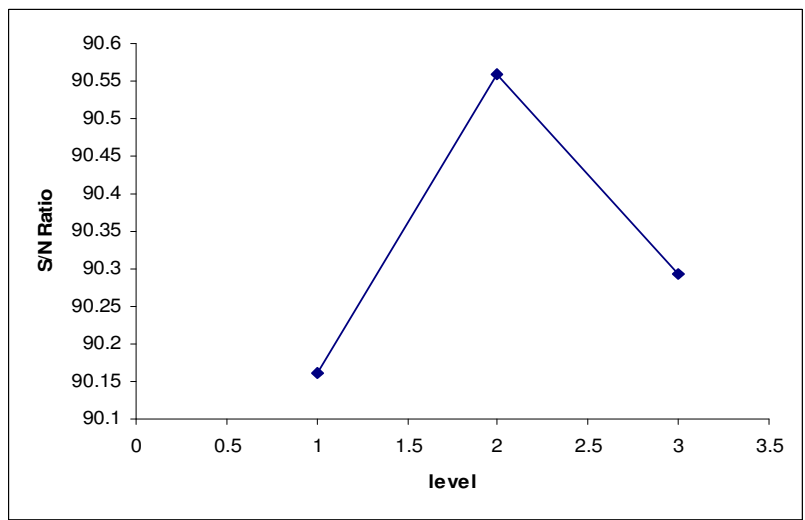

Figure 2. $\mathrm{S} / \mathrm{N}$ ratio for surface roughness with short pulse time.

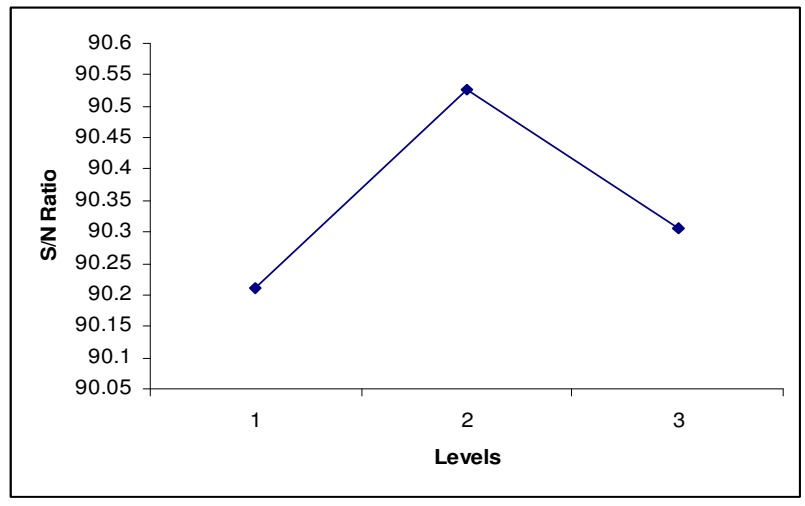

Figure 3. S/N ratio for surface roughness with time between pulses. 
Table 2. Experimental design using L27 orthogonal array.

\begin{tabular}{|c|c|c|c|c|c|c|c|c|c|c|c|c|c|}
\hline \multirow[b]{2}{*}{ Trial } & \multirow[b]{2}{*}{ A } & \multirow[b]{2}{*}{ B } & \multirow[b]{2}{*}{$\mathrm{C}$} & \multirow[b]{2}{*}{$\mathrm{D}$} & \multirow[b]{2}{*}{ E } & \multirow[b]{2}{*}{$\mathrm{F}$} & \multirow[b]{2}{*}{ G } & \multirow[b]{2}{*}{$\mathrm{H}$} & \multicolumn{5}{|c|}{$\operatorname{Ra}(\mu \mathrm{m})$} \\
\hline & & & & & & & & & Trial 1 & Trial 2 & Trial 3 & Mean & S.D \\
\hline 1 & 1 & 1 & 1 & 1 & 1 & 1 & 1 & 1 & 2.397 & 2.435 & 2.488 & 2.44 & 0.037 \\
\hline 2 & 1 & 1 & 1 & 1 & 2 & 2 & 2 & 2 & 3.142 & 3.034 & 3.184 & 3.12 & 0.066 \\
\hline 3 & 1 & 1 & 1 & 1 & 3 & 3 & 3 & 3 & 2.76 & 2.91 & 2.82 & 2.83 & 0.066 \\
\hline 4 & 1 & 2 & 2 & 2 & 1 & 1 & 1 & 2 & 2.54 & 2.464 & 2.532 & 2.51 & 0.04 \\
\hline 5 & 1 & 2 & 2 & 2 & 2 & 2 & 2 & 3 & 2.683 & 2.764 & 2.773 & 2.74 & 0.041 \\
\hline 6 & 1 & 2 & 2 & 2 & 3 & 3 & 3 & 1 & 3.12 & 2.965 & 3.065 & 3.05 & 0.064 \\
\hline 7 & 1 & 3 & 3 & 3 & 1 & 1 & 1 & 3 & 5.543 & 3.587 & 3.22 & 3.45 & 0.163 \\
\hline 8 & 1 & 3 & 3 & 3 & 2 & 2 & 2 & 1 & 3.14 & 3.415 & 3.045 & 3.2 & 0.156 \\
\hline 9 & 1 & 3 & 3 & 3 & 3 & 3 & 3 & 2 & 2.86 & 2.952 & 2.438 & 2.75 & 0.223 \\
\hline 10 & 2 & 1 & 2 & 3 & 1 & 2 & 3 & 1 & 3.45 & 3.154 & 3.066 & 3.22 & 0.167 \\
\hline 11 & 2 & 1 & 2 & 3 & 2 & 3 & 1 & 2 & 3.352 & 3.674 & 3.534 & 3.52 & 0.131 \\
\hline 12 & 2 & 1 & 2 & 3 & 3 & 1 & 2 & 3 & 3.58 & 3.86 & 3.69 & 3.71 & 0.115 \\
\hline 13 & 2 & 2 & 3 & 1 & 1 & 2 & 3 & 2 & 3.25 & 3.36 & 2.84 & 3.15 & 0.223 \\
\hline 14 & 2 & 2 & 3 & 1 & 2 & 3 & 1 & 3 & 3.30 & 3.35 & 3.28 & 3.31 & 0.029 \\
\hline 15 & 2 & 2 & 3 & 1 & 3 & 1 & 2 & 1 & 2.56 & 2.71 & 2.95 & 2.74 & 0.16 \\
\hline 16 & 2 & 3 & 1 & 2 & 1 & 2 & 3 & 3 & 3.62 & 3.53 & 3.62 & 3.59 & 0.042 \\
\hline 17 & 2 & 3 & 1 & 2 & 2 & 3 & 1 & 1 & 2.74 & 2.76 & 2.84 & 2.78 & 0.043 \\
\hline 18 & 2 & 3 & 1 & 2 & 3 & 1 & 2 & 2 & 3.61 & 3.59 & 3.65 & 3.62 & 0.025 \\
\hline 19 & 3 & 1 & 3 & 2 & 1 & 3 & 2 & 1 & 3.32 & 3.29 & 3.41 & 3.34 & 0.050 \\
\hline 20 & 3 & 1 & 3 & 2 & 2 & 1 & 3 & 2 & 3.1 & 3.4 & 3.1 & 3.2 & 0.141 \\
\hline 21 & 3 & 1 & 3 & 2 & 3 & 2 & 1 & 3 & 2.82 & 2.72 & 2.68 & 2.74 & 0.058 \\
\hline 22 & 3 & 2 & 1 & 3 & 1 & 3 & 2 & 2 & 3.31 & 3.42 & 3.29 & 3.34 & 0.057 \\
\hline 23 & 3 & 2 & 1 & 3 & 2 & 1 & 3 & 3 & 2.98 & 3.04 & 3.01 & 3.01 & 0.024 \\
\hline 24 & 3 & 2 & 1 & 3 & 3 & 2 & 1 & 1 & 2.93 & 2.97 & 2.95 & 2.95 & 0.016 \\
\hline 25 & 3 & 3 & 2 & 1 & 1 & 3 & 2 & 3 & 3.12 & 3.18 & 3.18 & 3.16 & 0.028 \\
\hline 26 & 3 & 3 & 2 & 1 & 2 & 1 & 3 & 1 & 2.84 & 2.86 & 2.91 & 2.87 & 0.029 \\
\hline 27 & 3 & 3 & 2 & 1 & 3 & 2 & 1 & 2 & 2.31 & 2.37 & 2.37 & 2.35 & 0.028 \\
\hline
\end{tabular}

Surface finish is good at high values of servo speed (Fig 4). Higher values of servo speed provides rapid removal of the eroded particles from the workpiece surface, which results in better surface finish. Figure 5 shows the $\mathrm{S} / \mathrm{N}$ ratio for surface roughness with servo reference voltage. An increase in servo reference mean voltage resulted in more number of ions and electrons collisions and more MRR, which leads to high surface roughness. Lower values of servo reference mean voltage gives better surface finish. $\mathrm{S} / \mathrm{N}$ ratio values of injection pressure are presented in Fig. 6. Less injection pressure eroded particles are not removed properly and it also influences the average temperature increment of the wire. At lower injection pressures, convective heat transfer coefficient is low which leads to high temperatures of the wire. But temperatures of the wire need to be low to maintain wire tension and MRR, which in turn influences the surface finish. Therefore, high injection pressures are required to maintain lower temperature of the wire and improved surface finish (Rajurkar and Wang, 1993).

Figure 7 demonstrates the relation between wire speed and surface roughness. Higher wire speed leads to rapid crossing of wire on the workpiece and amount of energy available to melt the material is low. At lower wire speeds, due to high amount of energy material removal rate increases which leads to lower surface finish. Hence medium wire speed is required to get better surface finish. $\mathrm{S} / \mathrm{N}$ ratio values of wire tension are presented in Fig. 8. If the wire tension is lower, wire can vibrate and results in poor surface finish. High wire tension may subject to wire breakage. Hence, wire tension should be medium. Among the selected levels in the present study, level 3 is given satisfactory results compared to other two levels. These results are agreeing with the previous work done by Ramakrishnan and Karunamurthy (2006). 


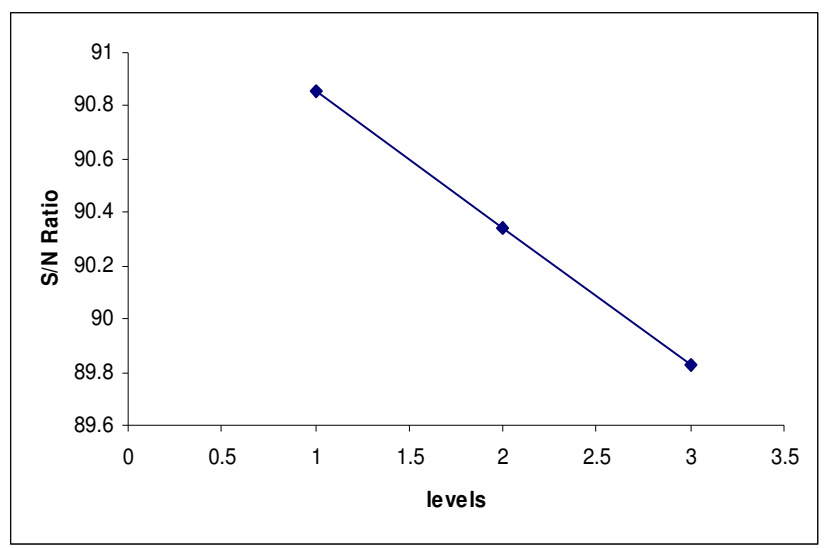

Figure 4. S/N ratio for surface roughness with servo speed.

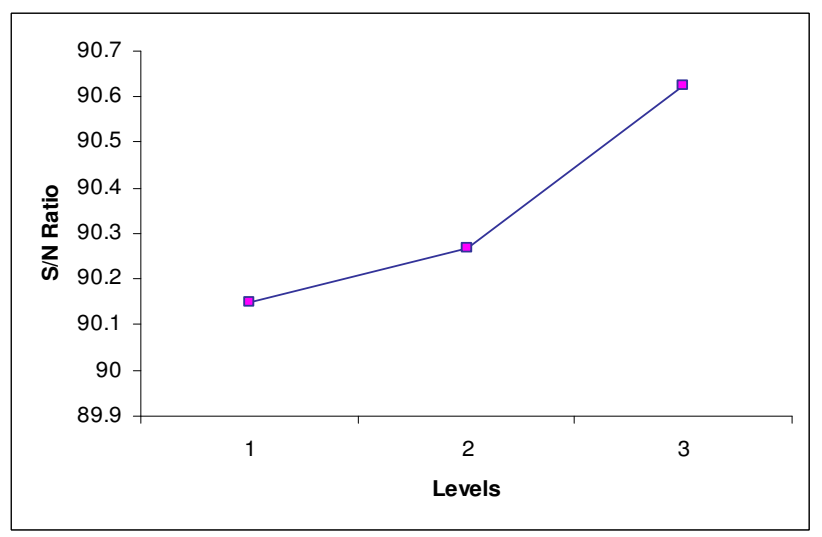

Figure 5. $\mathrm{S} / \mathrm{N}$ ratio for surface roughness with servo reference mean voltage.

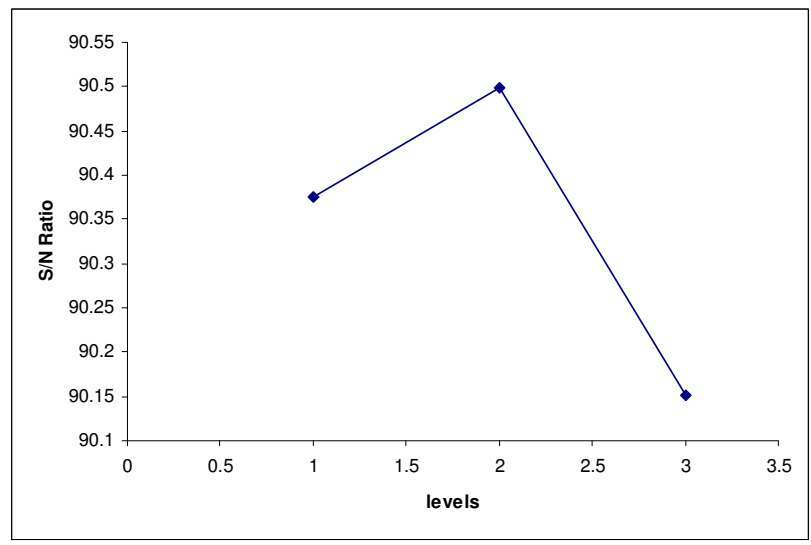

Figure 6. $\mathrm{S} / \mathrm{N}$ ratio for surface roughness with injection pressure.

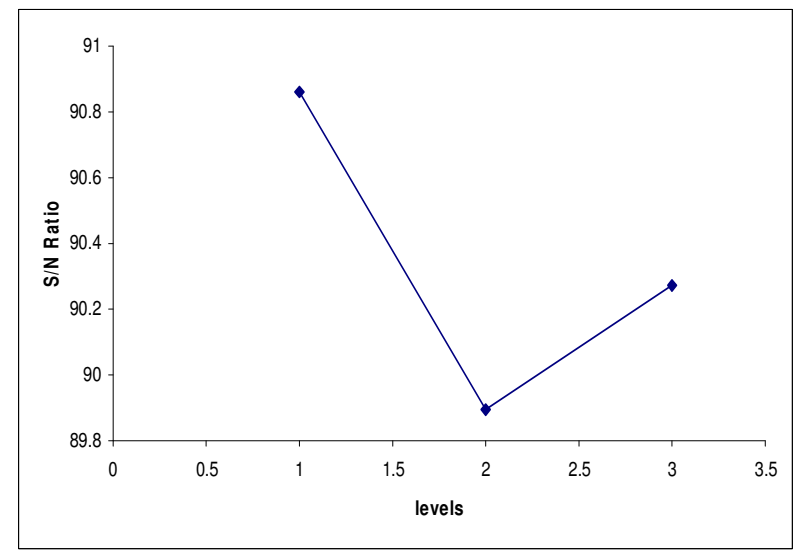

Figure 7. S/N ratio for surface roughness with wire speed.

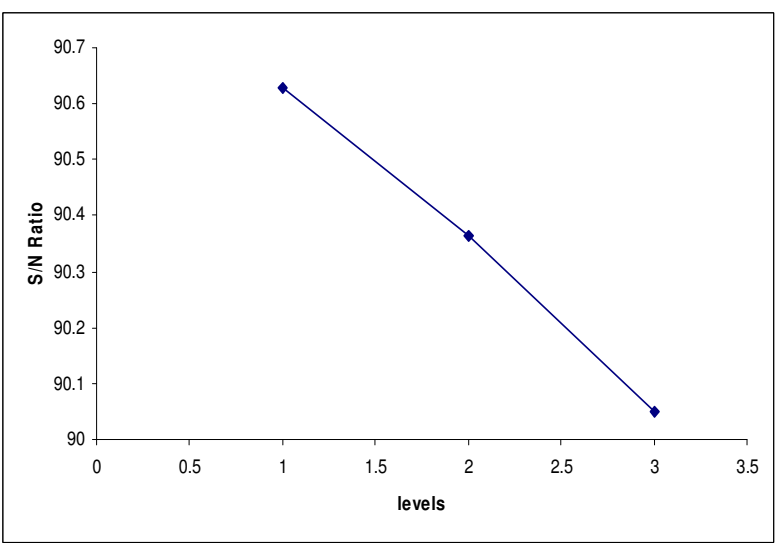

Figure 8 . S/N ratio for surface roughness with wire tension.

As observed in the response and $\mathrm{S} / \mathrm{N}$ ratio effect graphs, all the parameters considered in the study had at least some effect on the surface roughness and $\mathrm{S} / \mathrm{N}$ ratio. Analysis of the results leads to the conclusion that factors at level $A_{1}, B_{1}, C_{1}, D_{3}, E_{1}, F_{3}, G_{2}, H_{3}$ give better surface finish (Table 3 ).

Table 3. S/N Ratio response table for experimental results.

\begin{tabular}{|c|c|c|c|}
\hline \multicolumn{4}{|c|}{ S/N RESPONSE AT VARIOUS LEVELS } \\
\hline & LEVEL 1 & LEVEL 2 & LEVEL 3 \\
\hline A & 89.7 & 90.572 & 90.8175 \\
\hline B & 90.161 & 90.56 & 90.294 \\
\hline C & 90.212 & 90.527 & 90.307 \\
\hline D & 90.853 & 90.345 & 89.829 \\
\hline E & 90.151 & 90.269 & 90.626 \\
\hline F & 90.376 & 90.498 & 90.1515 \\
\hline G & 90.861 & 89.893 & 90.273 \\
\hline H & 90.63 & 90.364 & 90.051 \\
\hline
\end{tabular}




\section{Prediction Model}

In the present work, a mathematical model is selected to predict the surface roughness. In the model, Surface Roughness is assumed as function of ignition pulse current, short pulse time, time between two pulses, servo speed, servo reference voltage, injection pressure, wire speed, wire tension. The relationship between surface roughness and other input variables is modeled as follows:

$$
\begin{aligned}
& \mathrm{Ra}=\mathrm{K}_{1}+\mathrm{c}_{1} \mathrm{~A}+\mathrm{c}_{2} \mathrm{~B}+\mathrm{c}_{3} \mathrm{C}+\mathrm{c}_{4} \mathrm{D}+\mathrm{c}_{5} \mathrm{E}+ \\
& +\mathrm{c}_{6} \mathrm{~F}+\mathrm{c}_{7} \mathrm{G}+\mathrm{c}_{8} \mathrm{H}
\end{aligned}
$$

where $\mathrm{Ra}$ is surface roughness and constants $K_{1}$ and $c_{1}$ to $c_{8}$ are determined by linear regression analysis method using the experimental data. Commercially available SPSS ${ }^{\circledR}$ software is used to compute the regression constants. The developed model after substituting regression constants in Eq. (2) is as follows:

$\mathrm{Ra}=3.1674+0.0039 \mathrm{~A}-0.0009 \mathrm{~B}+0.0042 \mathrm{C}-$

$-0.0012 \mathrm{D}-0.0006 \mathrm{E}+0.0448 \mathrm{~F}+0.0093 \mathrm{G}-0.2868 \mathrm{H}$

The multiple regression coefficient of 0.943 is obtained in surface roughness prediction model. This shows that the developed regression model is significant.

\section{GA Approach}

The regression model is used to optimize the process parameters using GA, which works based on the mechanics of natural selection and genetics (Kalyanmoy Deb, 2001). The power of these algorithms is derived from a very simple heuristic assumption that the best solution will be found in the regions of solution space containing high proposition of good solution, and that these regions can be identified by judicious and robust sampling of the solution space. The mechanics of GA is simple, involving copying of binary strings and the swapping of the binary strings. The simplicity of operation and computational efficiency are the two main attractions of the GA approach. The computations are carried out in three stages to get a result in one generation or iteration. These three stages are reproduction, crossover and mutation.

Table 4. Tested range and best operating range of control factors from GA.

\begin{tabular}{|l|c|c|}
\hline Parameter & Tested range & Best operating range \\
\hline Ignition pulse current $(\mathrm{Amp})$ & $8-16$ & $8-11$ \\
\hline Short pulse duration $(\mu \mathrm{s})$ & $0.4-1.5$ & $0.4-0.6$ \\
\hline Time between two pulses $(\mu \mathrm{s})$ & $2-10$ & $3-6$ \\
\hline Servo speed $(\mu \mathrm{m} / \mathrm{min})$ & $2-15$ & $10-14$ \\
\hline Servo reference voltage $(\mathrm{V})$ & $10-80$ & $20-40$ \\
\hline Injection pressure $($ bar $)$ & $1-4$ & $3-4$ \\
\hline Wire speed $(\mathrm{m} / \mathrm{min})$ & $6-15$ & $9-11$ \\
\hline Wire tension $(\mathrm{dN})$ & $1-1.2$ & $1.125-1.2$ \\
\hline
\end{tabular}

Reproduction is the first of the genetic operators. It is a process in which copies of the strings are copied into a separate string called the 'mating pool', in proportion to their fitness values. This implies that strings with higher fitness values will have a higher probability of contributing more as the search progresses. Crossover operator is mostly responsible for the progress of the search. It swaps the parent strings partially, causing offspring to be generated. In this, a crossover site along the length of the string is selected randomly, and the portions of the strings beyond the crossover site are swapped. Mutation is one of last GA operators; this is the occasional random alteration (with a small probability) of the value of a string position. In binary strings, this simply means changing 1 to 0 , or vice versa.
The input control parameter levels are fed to the GA program, after using different types of crossover and mutation operators maximum and minimum values of surface roughness are predicted. This approach provides optimum machining conditions for corresponding, given maximum and minimum values of surface roughness. This gives the range of surface roughness values for a certain range of machining parameters. Table 4 shows the optimum machining conditions predicted by GA program after 50 trials of 500 generations each. The surface roughness values obtained in experimentation are very much comparable to the values obtained at the optimal range of control parameters.

\section{Conclusion}

In this work, an attempt is made to determine the optimal parameters for surface finish under varying conditions through the use of the Taguchi parameter design process in the WEDM of Ti6Al4V alloy. This process was applied using a specific set of control parameters, ignition pulse current, short pulse duration, time between two pulses, servo speed, servo reference voltage, injection pressure, wire speed and wire tension with a response variable of surface roughness. The use of the $\mathrm{L}_{27}\left(3^{8}\right)$ orthogonal array with eight control parameters and its effects on the response variable is studied experimentally. Surface roughness model with regression coefficient of 0.943 is obtained by regression analysis and the developed model is optimized by GA to obtain optimum control parameters. Surface roughness of $1.85 \mu \mathrm{m}$ is obtained with selected optimum control parameters in the WEDM of Ti6Al4V alloy.

\section{References}

Bradley, E.F., 1988, "Super alloys: A technical guide”, ASM International. Ezugwu, E.O., Da Silva, R.B., Bonney, J., Machado, A.R., 2005, "Evaluation of the performance of CBN tools when turning Ti-6Al-4V alloy with high pressure coolant supplies", International Journal of Machine Tools and Manufacture, Vol. 45, pp. 1009-1014.

Fuzhu Han, Jun Jiang, Dingwen Yu, 2007, "Influence of machining parameters on surface roughness in finish cut of WEDM", International Journal of Advanced Manufacturing Technology, Vol. 34, pp. 538-546.

Guedes, A., Pinto, A.M.P., Vieira, M., Viana, F., Ramos, A.S., Vieira, M.T., 2002, "Microstructural characterization of $\gamma$-TiAl Joints", Key Eng. Materials, Vol. 230-232, pp. 27-30.

Huang, J.T., Liao, Y.S., Hsue, W.J., 1999, "Determination of finish cutting operation number and machining parameters setting in wire electrical discharge machining", Journal of Materials Processing Technology, Vol. 87, pp. 69-81.

Jin Yuan, Kesheng Wang, Tao Yu, Minglun Fang, 2008, "Reliable multi-objective optimization of high-speed WEDM process based on Gaussian process regression”, International Journal of Machine Tools and Manufacture, Vol. 48, pp. 47-60.

Kalyanmoy Deb, 2001, "Multi-Objective Optimization Using Evolutionary Algorithms", John Wiley \& Sons, Inc., New York, NY.

Keith Hargrove, S., Duowen Ding, 2007, "Determining cutting parameters in wire EDM based on workpiece surface temperature distribution", International Journal of Advanced Manufacturing Technology, Vol. 34, pp. 295-299.

Liao, Y.S., Huang, J.T., Su, H.C., 1997, "A study on the machining parameters optimisation of wire electrical discharge machining", Journal of Materials Processing Technology, Vol. 71, No. 3, pp. 487-493.

Mahapatra, S.S., Amar Patnaik, 2007, "Optimization of wire electrical discharge machining (WEDM) process parameters using Taguchi method" International Journal of Advanced Manufacturing Technology, Vol. 34, No. 9-10, pp. 911-925.

Pan, B., Kim, D.J., Kim, B.M., Dean, T.A., 2001, "Incremental deformation and the forgeability of $\gamma$ titanium aluminide", International Journal of Machine Tools and Manufacture, Vol. 41, pp. 749-759.

Rajurkar, K.P., Wang, W.M., 1993, "Thermal modeling and on-line monitoring of wire-EDM", Journal of Materials Processing Technology, Vol. 38, No. 1-2, pp. 417-430.

Ramakrishnan, R., Karunamoorthy, L., 2006, "Multi response optimization of wire EDM operations using robust design of experiments", 
International Journal of Advanced Manufacturing Technology, Vol. 29, pp. 105-112.

Sarkar, S., Mitra, S., Bhattacharyya, B., 2006, "Parametric optimisation of wire electrical discharge machining of $\gamma$ titanium aluminide alloy through an artificial neural network model", International Journal of Advanced Manufacturing Technology, Vol. 2, pp. 501-508.

Shanjan, K. Shunmugam, M.S., 2004, "Characteristics of wire electro-discharge machined Ti6Al4V surface", Materials Letters, Vol. 58, pp. 2231-2237.

Shanjan, K., Shunmugam, M.S., 2005, "Multi-objective optimization of wire electro-discharge machining process by Non-dominated Sorting Genetic Algorithm”, Journal of Materials Processing Technology, Vol. 170, pp. 133-141
Scott, D., Boyina, S., Rajurkar, K.P., 1991, “Analysis and optimization of parameter combination in wire electrical discharge machining", International Journal of Production Research, Vol. 29, No. 11, pp. 2189-2207.

Tosun, N., Cogun, C., 2003, "An investigation on wire wear in WEDM", Journal of Materials Processing Technology, Vol. 134, No. 3, pp. 273-278.

Trezise, K.E., 1982, “A physicist's view of wire EDM”, Proceedings of the International Conference on Machine Tool Design and Research, Vol. 23, pp. 413-419.

Voice, W., 1999, "Future use of gamma titanium aluminides by RollsRoyce", Aircraft Engineering Aero Technology, Vol. 71, No. 4, pp. 337-340. 